\title{
Advanced Freeze-Thaw Assessment of Internally Integrated Concrete with Sodium Acetate
}

Mazen J. Al-Kheetan

mazen.al-kheetan@mutah.edu.jo

Civil and Environmental Engineering Department, Mutah University, Mutah, Karak, Jordan

Mujib M. Rahman

mujib.rahman@brunel.ac.uk

Department of Civil \& Environmental Engineering, Design and Physical Sciences, Brunel University, London, UK

Seyed Hamidreza Ghaffar

seyed.ghaffar@brunel.ac.uk

Department of Civil \& Environmental Engineering, Design and Physical Sciences, Brunel University, London, UK

\begin{abstract}
A new line of research is presented in this study where sodium acetate is used as a protective material for concrete. A newly developed freeze-thaw method that depends on the alteration of temperature and humidity is introduced in this research to investigate the efficacy of integrating sodium acetate with concrete with different water to cement ratios $(\mathrm{w} / \mathrm{c})$. Results from the introduced freeze-thaw method were compared with the outcomes of a standard freeze-thaw testing method. The distressed concrete was tested for water absorption and compressive strength after finishing six months of freeze-thaw testing. Results demonstrated the effectiveness of sodium acetate in protecting concrete
\end{abstract}

Keywords: Fresh concrete; Freezing and thawing; Sodium acetate; Concrete protection

\section{INTRODUCTION}

Concrete pavement is usually exposed to a combination of mechanical stresses and environmental impacts that accelerate its deterioration rate (Zhang et al., 2017; AlKheetan et al., 2019b). The presence of de-icing salts when in contact with the surface of concrete pavement during winter season can increase the damage of concrete, especially after their penetration in the pores with the absorbed water (Farnam et al., 2017; Farnam et al., 2015a; Farnam et al., 2015b; Al-Kheetan et al., 2019a; Sun et al., 2002). Add to that, the freezing and thawing cycles can produce a high pore pressure related to the water phase change inside the pores that work on initiating cracks within the concrete matrix (Li 2017). Accordingly, it is important to protect such structures from all the weathering actions and chemical attacks to keep it in its original form and serviceability (Tang et al., 2015; Mehta and Monteiro 2006).

Many protective materials have been used during the years to reduce the rate of deterioration caused by chloride and water ingress through concrete and to inhibit the freeze-thaw damage (Bertolini et al., 2013; Dry 2000; Lu and Zhou 2000; Al-Kheetan et al., 2017; Al-Kheetan et al., 2018a; Al-Kheetan et al., 2018b; Al-Kheetan et al., 2019c; Al-Kheetan et al., 2018c). Surface applied protective materials like silane and siloxane 
were the most widely used materials in this regard due to their high resistance to different environmental impacts and chemical attacks [Al-Kheetan et al., 2019c; Herb et al., 2015; De Vries and Polder 1997; Tittarelli and Moriconi 2008; Brenna et al., 2013; Falchi et al., 2015; Dai et al., 2010). However, few researches considered the protection of concrete pavement, in particular, either by using silane or any other surface applied materials (Al-Kheetan et al., 2019b). This refers to their inconvenient application method that requires closing the roads in front of vehicles and their effect on the frictional properties of concrete pavement (Al-Kheetan et al., 2019b). Accordingly, internally integrated materials were introduced to overcome all the issues associated with the surface applied materials (Cappellesso et al., 2016; Teng et al., 2014; Justnes et al., 2004; Kevern 2010; Ma et al., 2016).

The integration of sodium acetate into concrete for protection purposes is a newly introduced method that aims to improve the drawbacks that are associated with other traditional methods (Al-Otoom et al., 2007). After the mixing of sodium acetate with concrete, in the presence of water, it forms crystals that line the pores of concrete without blocking them. This material is characterised of being hygroscopic, as it works on absorbing water to form crystals that start to grow after the reaction of sodium acetate with water. After the formation of these crystals, they bond with concrete and work on repelling any excess water from the pores due to the development of hydrophobic properties that results from their reaction with cement during the hydration process (AlKheetan et al., 2019a).

In this research, two freeze-thaw conditions will be applied to concrete, and the performance of the used protective material, under these conditions, will be evaluated. In the first method, concrete was exposed to fast freeze-thaw cycles while it was immersed in water. This method has been widely used in previous studies but with less number of cycles than it is used in this research, where the number of cycles in this research is the highest until now (Zhang et al., 2017; Shang and Yi 2013; Jianxun et al., 2014; Shang et al., 2012; Wu and $\mathrm{Wu}$ 2014). In the second freeze-thaw method, a newly developed method is proposed where concrete is only in contact with air and under the effect of temperature change.

\section{MATERIALS AND TEST METHODS}

\subsection{Materials and specimens}

Four concrete mixtures with w/c ratios of $0.32,0.37,0.40$ and 0.46 were cast following the British Standard BS 1881-125 (British Standards Institution, 2013). A sodium acetate material with some cementitious content was added to all the mixes with two different ratios; $2 \%$ and $4 \%$ of the cement mass. In addition, a reference mix with $0 \%$ sodium acetate was cast for each mix design for comparison. Table 1 shows the proportions of each concrete mix that was used in this study. 
Table 1: Mix designs of the used concrete mixtures

\begin{tabular}{|c|c|c|c|c|}
\hline \multirow{2}{*}{ Ingredient } & \multicolumn{4}{|c|}{ Amount $\left(\mathbf{k g} / \mathbf{m}^{3}\right)$} \\
\cline { 2 - 5 } & $\mathrm{W} / \mathrm{C}=0.32$ & $\mathrm{~W} / \mathrm{C}=0.37$ & $\mathrm{~W} / \mathrm{C}=0.40$ & $\mathrm{~W} / \mathrm{C}=0.46$ \\
\hline $\begin{array}{c}\text { Cement }(\mathrm{CEM} \text { II/32.5 N; } \\
\text { Sulphates }<3.5 \% \text {, Chlo- } \\
\text { rides }<0.10 \% \text {, and initial } \\
\text { setting time around 1.25 h) }\end{array}$ & 513 & 491 & 450 & 457 \\
\hline Water & 164 & 182 & 180 & 210 \\
\hline $\begin{array}{c}\text { Fine aggregate (sharp silica } \\
\text { sand with uniform grain } \\
\text { size distribution between 1 } \\
\text { mm and 300 } \mu \text { m) }\end{array}$ & 658 & 660 & 678 & 660 \\
\hline $\begin{array}{c}\text { Coarse aggregate (crushed } \\
\text { stones with sharp edges and } \\
\text { maximum size of 20 mm) }\end{array}$ & 1068 & 1070 & 1092 & 1073 \\
\hline
\end{tabular}

72 concrete cubes with the dimensions of $100 \mathrm{~mm} \times 100 \mathrm{~mm} \times 100 \mathrm{~mm}$ were cast and divided into two groups; 36 cubes were tested for freeze-thaw cycles in air and 36 cubes were tested for fast freeze-thaw cycles in water. From each group, 9 cubes were prepared with $0.32 \mathrm{w} / \mathrm{c}$ ratio, 9 cubes with $0.37 \mathrm{w} / \mathrm{c}$ ratio, 9 cubes with $0.40 \mathrm{w} / \mathrm{c}$ ratio and 9 cubes with $0.46 \mathrm{w} / \mathrm{c}$ ratio. For each $\mathrm{w} / \mathrm{c}$ ratio, 3 cubes were integrated with $2 \%$ sodium acetate, 3 cubes with $4 \%$ sodium acetate and 3 cubes were used as control.

All concrete samples were cured in a water bath for 28 days. Afterwards, 36 cubes of them were placed in room temperature $\left(21^{\circ} \mathrm{C}\right)$ to dry so they can be tested under the freeze-thaw cycles in air. The other 36 cubes were placed in water for another 7 days until they were fully saturated (to achieve a constant mass).

\subsection{Test methods}

In the fast freeze-thaw test, cubes were placed in containers filled with water (cubes are immersed in water), and all containers were placed in Weiss-Voetsch Environmental Testing Chamber C340, following the guidelines of the Chinese standard GB/T 500822009 (China Academy of Building Research, 2009). Temperature was set to alternate between $-10{ }^{\circ} \mathrm{C}$ and $6{ }^{\circ} \mathrm{C}$ for a duration of 4 hours, representing a full rapid freeze-thaw cycle. The internal temperature of concrete cubes ranged between $-6^{\circ} \mathrm{C}$ and $4{ }^{\circ} \mathrm{C}$ during the freezing and thawing periods respectively. In total, 1080 freeze-thaw cycles during 6 months were carried out in this test.

In the newly developed freeze-thaw test, an environmental chamber that controls humidity and temperature was constructed. The chamber was constructed by utilising an existing industrial freezer as base for the freezing cycles and by introducing heating and humidity units inside the freezer to serve the thawing cycles. Furthermore, the heating and the humidity control units are additionally developed in order to complete the requirements for computer controlled scheduling of 24 hours cycles between temperatures of $-20{ }^{\circ} \mathrm{C}$ and $20{ }^{\circ} \mathrm{C}$, and constant humidity of $60 \%$. Cubes were placed inside the chamber and it was programmed to run for 6 continuous months with a total of 180 freeze-thaw cycles. The internal temperature of concrete was measured by using 
embedded thermocouples and it ranged between $17^{\circ} \mathrm{C}$ during the thawing process and $-16{ }^{\circ} \mathrm{C}$ during the freezing process.

The ability of the sodium acetate compound to preserve concrete from water ingress in harsh environments was assessed by running the ISAT test on the distressed samples (after finishing the freeze-thaw tests). Initial Surface Absorption Test (ISAT) was used to measure the uniaxial water absorption of concrete cubes by following the guidelines of BS 1881-208 (Al-Kheetan et al., 2020; British Standards Institution, 1996).

Mechanical properties of concrete were determined by running the compressive strength test on all the samples after finishing the freeze-thaw cycles, following the British Standard BS EN 12390-3 (British Standards Institution, 2009). Furthermore, the obtained results were compared with the compressive strength results of the samples before running the freeze-thaw tests.

\section{RESULTS AND DISCUSSION}

\subsection{Water absorption (after freeze-thaw)}

Concrete samples have shown a general increase in water absorption after the impact of freeze-thaw cycles in water. Figure 1 demonstrates the water absorption rate of concrete after the impact of 1080 cycles under the immersion effect.

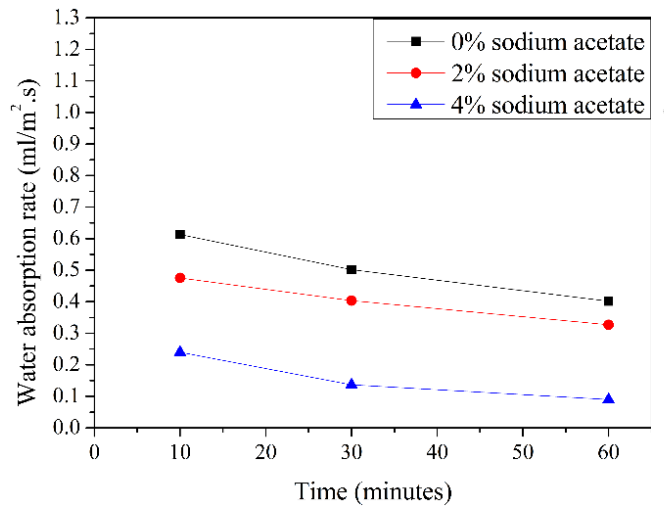

(a)

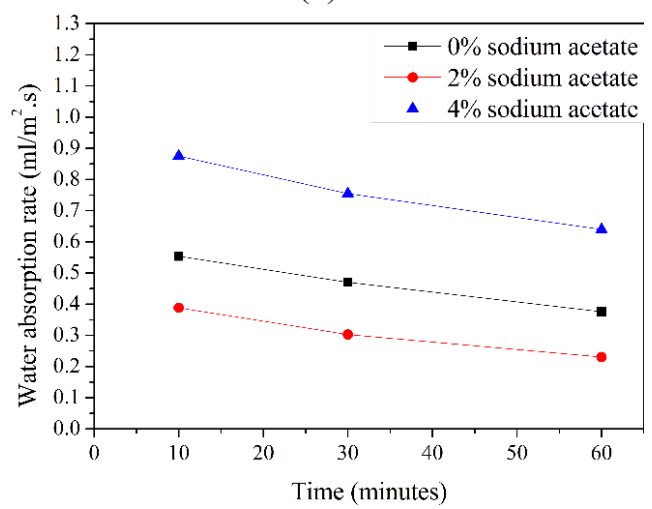

(c)

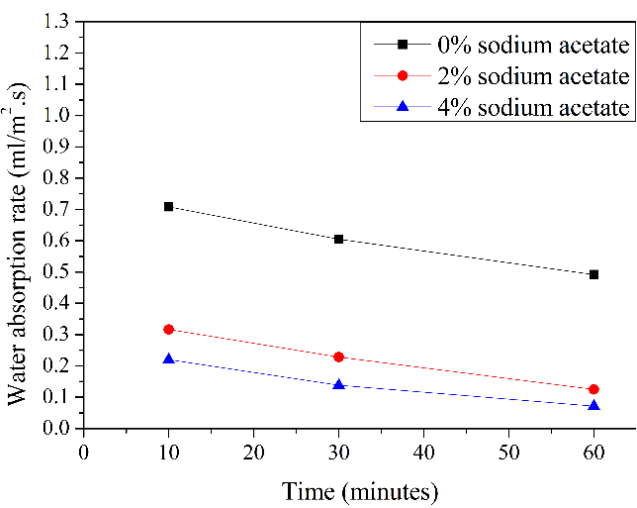

(b)

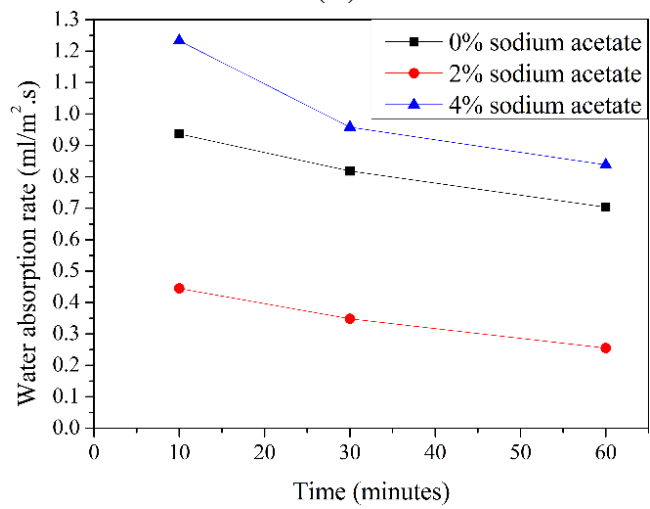

(d)

Figure 1: Water absorption of concrete after the impact of 1080 freeze-thaw cycles in water for concrete with w/c ratio of: (a) 0.32 , (b) 0.37 , (c) 0.40 and (d) 0.46 
Concrete samples with w/c ratios of 0.32 and 0.37 treated with $4 \%$ sodium acetate show the least water absorption rates among all mixtures. This amount of treatment helped water absorption rate drop by $78 \%$ and $85 \%$ for mixtures with 0.32 and $0.37 \mathrm{w} / \mathrm{c}$ ratios respectively, compared to their control mixtures (Figure $1 \mathrm{a}$ and $\mathrm{b}$ ). Even when both mixtures were treated with $2 \%$ sodium acetate, they have shown a high ability to reduce water absorption. This might be a result of using a compatible amount of water and sodium acetate, where no excess water is present in the mix and the amount of water was suitable to initiate the reaction between sodium acetate and cement, and the same time water was enough to continue the hydration process.

In the case of concrete with w/c ratios of 0.40 and 0.46 treated with $4 \%$ sodium acetate, an obvious destructive effect could be seen from Figure $1 \mathrm{c}$ and $\mathrm{d}$. Water absorption of these two mixes significantly increased, compared to their control and to other mixtures after the impact of freeze-thaw. This might refer to their high porosity when they were first cast and the formation of some microcracks in concrete after the impact of freeze-thaw cycles. Moreover, the high w/c ratio, especially in concrete with $\mathrm{w} / \mathrm{c}$ ratio of 0.46 , and the highly added dosage of the sodium acetate compound will contribute in increasing the formation of the hydrophobic organosilicon content. The presence of this hydrophobic content in large amounts in concrete at early ages will probably work on reducing the needed amount for the hydration process by repelling water out from concrete. This will lead to the formation of some microcracks in concrete during its curing and before initiating the freeze-thaw test. With the impact of the freezethaw test, these microcracks will develop into larger cracks, and concrete will absorb more quantities of water.

Referring to the results of water absorption of concrete under the impact of 180 freezethaw cycles in air, a clear increase in permeability can be noticed. Figure 2 illustrates the effect of freeze-thaw cycles in air on absorption of water by the concrete.

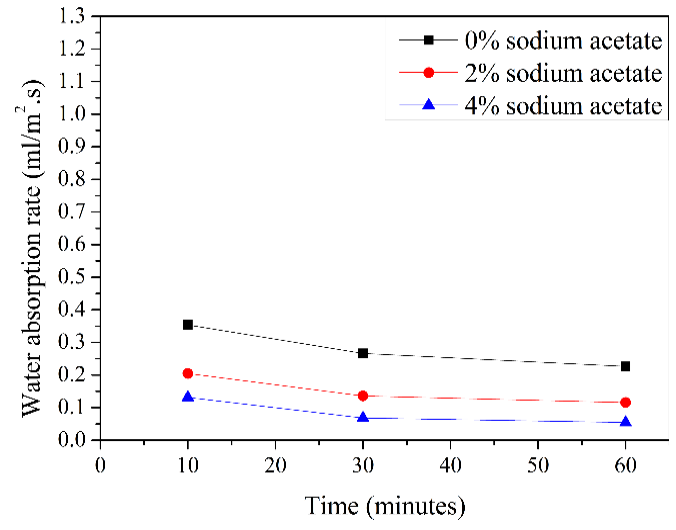

(a)

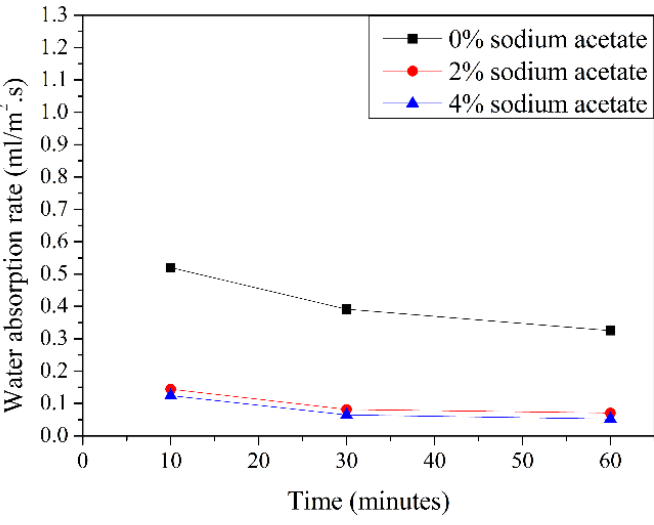

(b) 


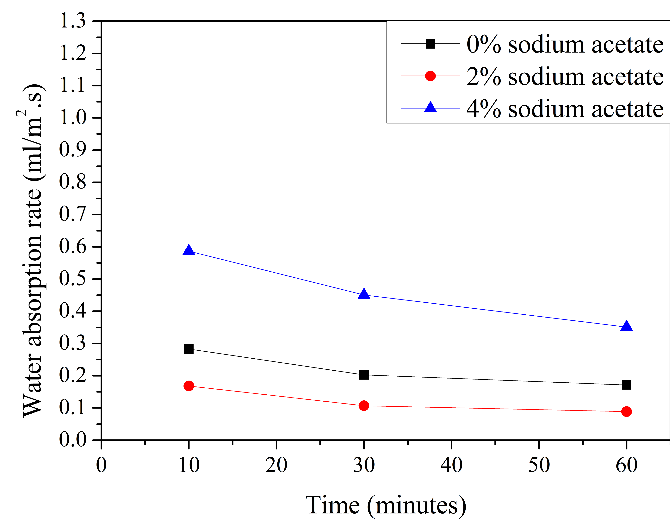

(c)

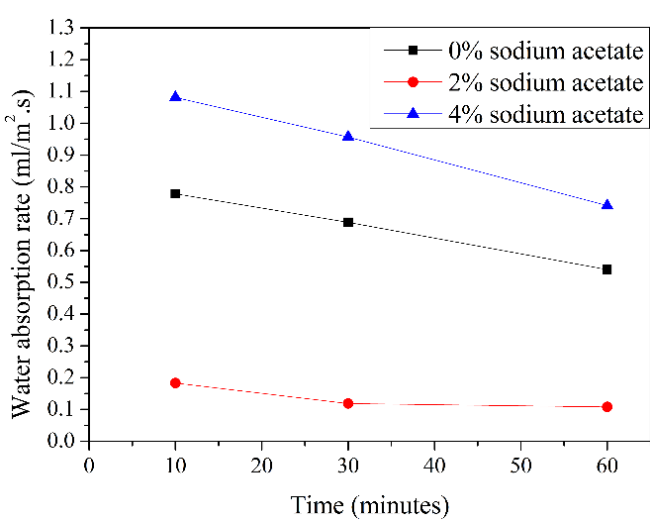

(d)

Figure 2: Water absorption of concrete after the impact of 180 freeze-thaw cycles in air for concrete with w/c ratio of: (a) 0.32 , (b) 0.37 , (c) 0.40 and (d) 0.46

Water absorption rates under the effect of air have followed a similar trend to that in water but with less absorbing rates. This is expected since the severity of the test in water is higher than that in air.

Similar to the freeze-thaw test in water, concrete with w/c ratios of 0.32 and 0.37 treated with $4 \%$ sodium acetate have shown the least absorption rate between all mixes, which refers to the compatibility between the used amount of water and the added percentage of the admixture.

On the other hand, concrete with w/c ratios of 0.40 and 0.46 treated with $4 \%$ sodium acetate suffered increase in the absorption rate of water. This issue could be explained by following the same reasons for their high absorption rates after the impact of freeze-thaw cycles in water. In addition, their high tendency to absorb moisture during freeze-thaw in air confirms with the current outcomes, because of the formation of large microcracks and the original high porosity of concrete.

\subsection{Compressive strength (after freeze-thaw)}

After finishing both freeze-thaw tests, in water and air, all samples have been tested for compressive strength to measure the ability of treatment for preserving the strength of concrete in harsh conditions. Table 2 shows the compressive strength and standard deviation values of concrete after their exposure to cyclic freeze-thaw in water and air.

Table 2: Compressive strength of concrete after the impact of freeze-thaw cycles

\begin{tabular}{|c|c|c|c|c|c|c|c|c|c|c|c|c|c|}
\hline & \multicolumn{12}{|c|}{ Compressive strength (MPa) } \\
\hline & & \multicolumn{6}{|c|}{ Freeze-thaw in water } & \multicolumn{6}{|c|}{ Freeze-thaw in air } \\
\hline & & $0 \%$ & SD & $2 \%$ & SD & $4 \%$ & SD & $0 \%$ & SD & $2 \%$ & SD & $4 \%$ & SD \\
\hline \multirow{4}{*}{$\begin{array}{l}\text { w/c } \\
\text { ratio }\end{array}$} & 0.32 & 38.7 & 1.1 & 42.1 & 1.5 & 50.5 & 0.7 & 38.8 & 0.9 & 47.7 & 1.6 & 53.5 & 0.8 \\
\hline & 0.37 & 31.2 & 0.9 & 39.2 & 1.3 & 46 & 2 & 34.8 & 2.8 & 45.2 & 2.3 & 50.5 & 1.3 \\
\hline & 0.40 & 45.5 & 1.2 & 36.4 & 1.2 & 32.9 & 0.2 & 54.4 & 1.8 & 42.1 & 1.9 & 43.3 & 0.3 \\
\hline & 0.46 & 36.1 & 0.8 & 29.1 & 1 & 21.2 & 0.4 & 45.1 & 2.3 & 37 & 1.6 & 30.3 & 1.6 \\
\hline
\end{tabular}


It is witnessed that concrete under the impact of cyclic freeze-thaw in water suffered from a drop in its compressive strength values when compared to concrete under freezethaw cycles in air. Once more, this refers to the severity of the applied conditions in the case of the freeze-thaw test in water. The frost action of the freeze-thaw test in water may damage the internal pores of concrete due to the presence of water inside the pores. The expansion of water inside the pores will damage the pore system and initiate cracks inside the concrete, which in turn will weaken it and reduce its strength.

\section{CONCLUSION}

The long-term performance of concrete treated with $2 \%$ and $4 \%$ sodium acetate has been tested through two freeze-thaw tests that operate differently; freeze-thaw under the effect of water and freeze-thaw under the effect of air. Both tests have run for 6 continuous months but with different number of cycles and different speeds. In the freeze-thaw test under the effect of water, saturated concrete was immersed in water and placed under the impact of fast 1080 freeze-thaw cycles during the 6 months. However, in the freeze-thaw test under the effect of air, concrete was under the impact of slow temperature alteration with 180 cycles during the 6 months. Both tests have been destructive to concrete but with severer effect in the case of freeze-thaw cycles in water.

Concrete with low w/c ratios of 0.32 and 0.37 have managed to resist deterioration more than concrete with high w/c ratios of 0.40 and 0.46 . Treating the low w/c ratio concrete with the sodium acetate compound has increased its resistance to deterioration unlike the high $\mathrm{w} / \mathrm{c}$ ratio concrete. Treating high w/c ratio with sodium acetate has increased its deterioration rate more than untreated concrete, and deterioration was noticed to increase with increasing the added dosage of treatment. The opposite was noticed in the low $\mathrm{w} / \mathrm{c}$ ratio concrete, where increasing the dosage has improved concrete resistance to deterioration. After both freeze-thaw tests have finished, water absorption and compressive strength of the deteriorated concrete were evaluated. All concrete samples have shown an increase in water absorption. However, this increase was minimum in the case of concrete with low w/c ratio, especially when treated with $4 \%$ sodium acetate. The maximum absorption rate was noticed in concrete with 0.46

$\mathrm{w} / \mathrm{c}$ ratio and treated with $4 \%$ sodium acetate. Similar results were noticed after testing the deteriorated concrete for compressive strength. However, in the case of concrete that went through the air cyclic freeze-thaw, its compressive strength values did not change and remained similar to original values of non-deteriorated concrete.

\section{REFERENCES}

Al-Kheetan, M. J., Ghaffar, S.H., Madyan, O. A. \& Rahman, M. M. (2020). Development of low absorption and high-resistant sodium acetate concrete for severe environmental conditions. Construction and Building Materials, 230, pp. 117057.

Al-Kheetan, M. J., Rahman, M., Muniswamappa, B. N. \& Chamberlain, D. (2019c). Performance enhancement of self-compacting concrete in saline environment by Hydrophobic surface protection. Canadian Journal of Civil Engineering.

Al-Kheetan, M. J., Rahman, M. M. \& Chamberlain, D. A., (2017). Influence of early water exposure on modified cementitious coating. Construction and Building Materials, 141, pp. 
64-71.

Al-Kheetan, M. J., Rahman, M. M. \& Chamberlain, D. A. (2018a). A novel approach of introducing crystalline protection material and curing agent in fresh concrete for enhancing hydrophobicity. Construction and Building Materials, 160, pp. 644-652.

Al-Kheetan, M. J., Rahman, M. M. \& Chamberlain, D. A. (2018b). Development of hydrophobic concrete by adding dual-crystalline admixture at mixing stage. Structural Concrete, 19(5), pp. 1504-1511.

Al-Kheetan, M. J., Rahman, M. M. \& Chamberlain, D. A. (2018c). Remediation and protection of masonry structures with crystallising moisture blocking treatment. International Journal of Building Pathology and Adaptation, 36(1), pp.77-92.

Al-Kheetan, M. J., Rahman, M. M. \& Chamberlain, D. A., (2019a). Fundamental interaction of hydrophobic materials in concrete with different moisture contents in saline environment. Construction and Building Materials, 207, pp. 122-135.

Al-Kheetan, M. J., Rahman, M. M. \& Chamberlain, D.A., (2019b). Moisture evaluation of concrete pavement treated with hydrophobic surface impregnants. International Journal of Pavement Engineering.

Al-Otoom, A., Al-Khlaifa, A. \& Shawaqfeh, A. (2007). Crystallization technology for reducing water permeability into concrete. Industrial \& engineering chemistry research, 46(16), pp. 5463-5467.

Bertolini, L., Elsener, B., Pedeferri, P., Redaelli, E. \& Polder, R.B. (2013). Corrosion of steel in concrete: prevention, diagnosis, repair. John Wiley \& Sons.

Brenna, A., Bolzoni, F., Beretta, S. \& Ormellese, M. (2013). Long-term chloride-induced corrosion monitoring of reinforced concrete coated with commercial polymer-modified mortar and polymeric coatings. Construction and Building Materials, 48, pp. 734-744.

British Standards Institution BS 1881-125 (2013). Testing concrete. Methods for mixing and sampling fresh concrete in the laboratory, British Standards Institution, London.

British Standards Institution BS 1881-208 (1996). Testing concrete. Recommendations for the determination of the initial surface absorption of concrete, British Standards Institution, London.

British Standards Institution BS EN 12390-3 (2009). Testing Hardened Concrete. Compressive Strength of Test Specimens, British Standards Institution, London.

Cappellesso, V.G., dos Santos Petry, N., Dal Molin, D.C.C. \& Masuero, A. B. (2016). Use of crystalline waterproofing to reduce capillary porosity in concrete. Journal of Building Pathology and Rehabilitation, 1(1), p. 9.

China Academy of Building Research (2009). GB/T 50082-2009 Standard for test methods of long-term performance and durability of ordinary concrete, Ministry of Housing and Urbanrural Development of China, Beijing, pp. 10-14.

Dai, J. G., Akira, Y., Wittmann, F. H., Yokota, H. \& Zhang, P. (2010). Water repellent surface impregnation for extension of service life of reinforced concrete structures in marine environments: the role of cracks. Cement and Concrete Composites, 32(2), pp.101-109.

De Vries, J. \& Polder, R. B. (1997). Hydrophobic treatment of concrete. Construction and Building Materials, 11(4), pp. 259-265.

Dry, C. M. (2000). Three designs for the internal release of sealants, adhesives, and waterproofing chemicals into concrete to reduce permeability. Cement and Concrete Research, 30(12), pp. 1969-1977. 
Falchi, L., Zendri, E., Müller, U. \& Fontana, P. (2015). The influence of water-repellent admixtures on the behaviour and the effectiveness of Portland limestone cement mortars. Cement and Concrete Composites, 59, pp. 107-118.

Farnam, Y., Dick, S., Wiese, A., Davis, J., Bentz, D. \& Weiss, J. (2015b). The influence of calcium chloride deicing salt on phase changes and damage development in cementitious materials. Cement and Concrete Composites, 64, pp. 1-15.

Farnam, Y., Esmaeeli, H. S., Zavattieri, P. D., Haddock, J. \& Weiss, J. (2017). Incorporating phase change materials in concrete pavement to melt snow and ice. Cement and Concrete Composites, 84, pp. 134-145.

Farnam, Y., Wiese, A., Bentz, D., Davis, J. \& Weiss, J. (2015a). Damage development in cementitious materials exposed to magnesium chloride deicing salt. Construction and Building Materials, 93, pp. 384-392.

Herb, H., Gerdes, A. \& Brenner-Weiß, G., (2015). Characterization of silane-based hydrophobic admixtures in concrete using TOF-MS. Cement and Concrete Research, 70, pp. 77-82.

Jianxun, C., Xizhong, Z., Yanbin, L., Xianghui, D. \& Qin, L. (2014). Investigating freeze-proof durability of C25 shotcrete. Construction and Building materials, 61, pp. 33-40.

Justnes, H., Østnor, T. A. \& Barnils Vila, N. (2004). October. Vegetable oils as water repellents for mortars. In Proceedings of the 1st international conference of Asian concrete federation, Chiang Mai (pp. 28-29).

Kevern, J. T. (2010). Using Soybean Oil to Improve the Durability of Concrete Pavements. International Journal of Pavement Research and Technology, 3(5), pp. 280-285.

Li, K. (2017). Durability Design of Concrete Structures: Phenomena, Modeling, and Practice. John Wiley \& Sons.

Lu, Z. \& Zhou, X. (2000). The waterproofing characteristics of polymer sodium carboxymethylcellulose. Cement and concrete research, 30(2), pp. 227-231.

Ma, Z., Wittmann, F. H., Xiao, J. \& Zhao, T. (2016). Influence of freeze-thaw cycles on properties of integral water repellent concrete. Journal of Wuhan University of Technology-Mater. Sci. Ed., 31(4), pp. 851-856.

Mehta, P. K. \& Monteiro, P. J. M. (2006). Concrete: microstructure, properties, and materials. 3rd edn. New York; London: McGraw-Hill.

Shang, H. S. \& Yi, T. H. (2013). Freeze-thaw durability of air-entrained concrete. The Scientific World Journal.

Shang, H. S., Yi, T. H. \& Song, Y. P. (2012). Behavior of plain concrete of a high water-cement ratio after freeze-thaw cycles. Materials, 5(9), pp. 1698-1707.

Sun, W., Mu, R., Luo, X. \& Miao, C. (2002). Effect of chloride salt, freeze-thaw cycling and externally applied load on the performance of the concrete. Cement and Concrete Research, 32(12), pp. 1859-1864.

Tang, S. W., Yao, Y., Andrade, C. \& Li, Z. J. (2015). Recent durability studies on concrete structure. Cement and Concrete Research, 78, pp. 143-154.

Teng, L. W., Huang, R., Chen, J., Cheng, A. \& Hsu, H. M. (2014). A study of crystalline mechanism of penetration sealer materials. Materials, 7(1),pp.399-412.

Tittarelli, F. \& Moriconi, G. (2008). The effect of silane-based hydrophobic admixture on corrosion of reinforcing steel in concrete. Cement and Concrete Research, 38(11), pp. 1354-1357.

$\mathrm{Wu}$, Y. \& Wu, B. (2014). Residual compressive strength and freeze-thaw resistance of ordinary 
concrete after high temperature. Construction and Building Materials, 54, pp. 596-604.

Zhang, P., Wittmann, F. H., Vogel, M., Müller, H. S. \& Zhao, T. (2017). Influence of freeze-thaw cycles on capillary absorption and chloride penetration into concrete. Cement and Concrete Research, 100, pp. 60-67.

Zhang, P., Wittmann, F. H., Vogel, M., Müller, H. S. \& Zhao, T. (2017). Influence of freeze-thaw cycles on capillary absorption and chloride penetration into concrete. Cement and Concrete Research, 100, pp. 60-67. 